\title{
Trichomonas vaginalis perturbs the junctional complex in epithelial cells
}

\author{
Rodrigo Furtado MADEIRO da COSTA ${ }^{1,2}$, Wanderley de SOUZA $^{2,3}$, Marlene BENCHIMOL ${ }^{4}$, John F ALDERETE ${ }^{5}$, \\ José Andrés MORGADO-DÍAZ ${ }^{2, *}$ \\ ${ }^{1}$ Programa de Pós Graduação em Ciências Morfológicas, Universidade Federal do Rio de Janeiro, Rio de Janeiro, RJ 20231 - \\ 050, Brazil \\ ${ }^{2}$ Grupo de Biologia Estrutural, Divisão de Biologia Celular, Centro de Pesquisa, Instituto Nacional de Câncer, Rio de \\ Janeiro, RJ 20231-050, Brazil \\ ${ }^{3}$ Laboratório de Ultraestrutura Celular Hertha Meyer, Instituto de Biofísica Carlos Chagas Filho, Universidade Federal do \\ Rio de Janeiro, Centro de Ciências da Saúde, Rio de Janeiro, RJ 21944-900, Brazil \\ ${ }^{4}$ Laboratório de Ultraestrutura Celular, Universidade Santa Úrsula, Rio de Janeiro, RJ 22231-010, Brazil \\ ${ }^{5}$ Department of Microbiology, University of Texas Health Science Center, San Antonio, TX 78229-3900, USA
}

\begin{abstract}
Trichomonas vaginalis, a protist parasite of the urogenital tract in humans, is the causative agent of trichomonosis, which in recent years have been associated with the cervical cancer development. In the present study we analyzed the modifications at the junctional complex level of Caco-2 cells after interaction with two isolates of $T$. vaginalis and the influence of the iron concentration present in the parasite's culture medium on the interaction effects. Our results show that $T$. vaginalis adheres to the epithelial cell causing alterations in the junctional complex, such as: (a) a decrease in transepithelial electrical resistance; (b) alteration in the pattern of junctional complex proteins distribution as observed for E-cadherin, occludin and ZO-1; and (c) enlargement of the spaces between epithelial cells. These effects were dependent on (a) the degree of the parasite virulence isolate, (b) the iron concentration in the culture medium, and (c) the expression of adhesin proteins on the parasite surface.
\end{abstract}

Keywords: Trichomonas vaginalis, Caco-2, junctional complex proteins, transepithelial electrical resistance, adhesins.

\section{INTRODUCTION}

Trichomonas vaginalis, a protozoan parasite, is the causative agent of trichomoniasis, the most common nonviral sexually transmitted disease in humans [1]. This parasite has a worldwide distribution and it infects 250 to 350 million people worldwide [2]. Trichomonose causes a serious discomfort to women, and is associated with adverse pregnancy outcome, manifested by preterm rupture of membranes, preterm delivery, and low-birth-weight infants $[3,4]$, and infertility [5], cervical cancer $[6,7]$,

*Correspondence: José Andrés MORGADO-DÍAZ

Grupo de Biologia Estrutural, Divisão de Biologia Celular, Centro de Pesquisas, Instituto Nacional de Câncer, Rua André Cavalcante, 37, Rio de Janeiro, RJ, 20231-050, Brazil.

Tel: +55-021-32331325; Fax: +55-021-32331470.

E-mail: jmorgado@inca.gov.br and increase in the transmission of human immunodeficiency virus [8-10]. Despite several advances that have been made in understanding the interaction between $T$. vaginalis and host cells, as well as in dissecting the steps in the invasion process [11], the cellular mechanisms of $T$. vaginalis pathogenesis are not well defined.

A major role in the pathogenesis of the trichomoniasis has been attributed to the adherence to host cells and damage by a contact-dependent mechanism [11-14]. Studies carried out with Entamoeba histolytica, a protozoa which interacts with intestinal epithelial cells, have shown that one important step of the interaction process is the disturbance of the epithelium integrity [15]. Interference with the cell-to-cell adhesion, which can be evaluated by integrity of tight junctions, is one of the first indications of epithelium injury. Recently, Guenthner et al [16] postulated two mechanisms that could contribute to the epidemiological association of trichomoniasis with the sexual transmis- 
sion of HIV-1. One of them establishes that, disruption of urogenital epithelial monolayers by $T$. vaginalis could facilitate passage of the virus to underlying layers. Adherence of $T$. vaginalis to epithelial cells is a complex process where four surface proteins (AP65, AP51, AP33, and AP23) play some role [12]. These proteins interact with host cells via ligand-receptor-type interactions [17]. Furthermore, it has been reported that transcription and expression of genes coding for these proteins are greatly influenced by iron concentration in the medium where the protozoan was cultivated [18-20]. Pathogenicity is also influenced by cellular contact between pathogens and the epithelial cells, culminating in disturbance of the junctional complex [14, 21-23].

The junctional complex is responsible for maintenance of the integrity of intercellular contacts and is composed by two main structures: adherent and tight junctions. The former is responsible for homophilic calcium-dependent contact between adjacent cells [24-26], and the latter is responsible for regulating paracellular permeability, maintaining different cell domains and epithelial polarity $[27,28]$. The molecular architecture and regulation of tight junctions are still unresolved; however, it is well established that integral proteins named occludin and claudins are important constituents of this structure [29, 30]. Both proteins are found associated with the peripheral plasma membrane protein $\mathrm{ZO}-1$, at the cytosolic face. Occludin binds directly through its carboxyl terminus to ZO-1 [31] and it is also associated with ZO-3 [32]. ZO-1 is, in turn, associated with ZO-2 [33] and AF-6 [34]. The adherent junction is very important for solid tissues maintenance and is mediated by a group of proteins named cadherins.

These proteins are $\mathrm{Ca}^{2+}$ dependent homophilic receptors and are fundamental for cell recognition and sorting during development [35]. It is established that junctional complex components are linked to actin cytoskeleton [36].

Disturbance of the junctional complex may take place as a consequence of microbiological infections. The present work addresses the question whether epithelial functional disturbance caused by $T$. vaginalis is associated with molecular alterations in the junctional complex of Caco-2 cells, an epithelial human colonic adenocarcinoma. This cell line was selected since it is widely used to analyze the structure and physiology of an epithelium in vitro and due to the fact that at present there is no equivalent experimental system with urogenital cells.

\section{MATERIAL AND METHODS}

\section{Epithelial cells}

Caco-2 cells were obtained from American Type Culture Collection (ATCC, \# HTB-37, Manassas, VA) and were grown in culture flasks (TPP, Switzerland) using high glucose Dubelcco's modified Eagle's medium (DMEM) supplemented with $10 \%$ fetal calf serum (Gibco BRL, Gaithersburg, MD), $0.1 \mathrm{~g} / \mathrm{L}$ streptomycin, and $100 \mathrm{U} /$ $\mathrm{ml}$ penicillin. Cultures were maintained at $37^{\circ} \mathrm{C}$ in a $5 \% \mathrm{CO}_{2}$ atmosphere. All experiments were performed when culture achieved confluence.

\section{Parasite}

The JT isolate of T. vaginalis was isolated at the Hospital Universitário Clementino Fraga Filho, Universidade Federal do Rio de Janeiro Brazil, and has been maintained in culture for several years. T016 isolate is a fresh isolate kindly provided by Dr. Alderete (University of Texas Health Science Center at San Antonio, USA) and has been maintained in culture for no longer than $15 \mathrm{~d}$, with daily passages. Both strains were cultivated in Trypticase-yeast extractmaltose (TYM) medium [37] supplemented with 10\% fetal calf serum, here named high iron medium (HI). Low iron medium (LI) cultures were prepared by adding $50 \mathrm{mM}$ of the iron chelator 2,2-dipyridil (2, 2DP) (Sigma Chemical Co., St Louis, MO) for $24 \mathrm{~h}$ in $10^{5}$ organisms/ $\mathrm{ml}$ cultures. These cultures were then centrifuged at $150 \times \mathrm{g}$ for $5 \mathrm{~min}$ and resuspended in TYM medium supplemented with $75 \mathrm{mM} \mathrm{2,}$ 2DP for a further $24 \mathrm{~h}$ before interaction assays [38].

\section{Epithelial cells/parasite interaction procedures}

Caco-2 cells were grown on sterile glass coverslips until confluence was reached. One hour before interaction assays, cells were washed in sterile PBS and growth medium was replaced by fresh medium and incubated at $37^{\circ} \mathrm{C}$ for at least $1 \mathrm{~h}$ before interaction. After parasites have reached the density of $10^{6}$ organisms $/ \mathrm{ml}$ culture tubes were chilled for parasite detachment and centrifuged at $150 \times \mathrm{g}$. The supernatant was discarded and the pellet resuspended in interaction medium (DMEM: TYM, 2:1).

\section{Interaction rate assay}

In order to determine the interaction level of the parasites with the Caco-2 cells, a preliminary experiment was performed using different parasite densities $(10: 1,5: 1,3: 1,2: 1$ and 1:1). Parasites interacting with Caco-2 cultures were monitored during $120 \mathrm{~min}$. Cell counting was performed every 30 min by gently washing the cultures and fixing them with $4 \%$ paraformaldehyde. Cells were washed and stained with Giemsa for $5 \mathrm{~min}$ and observed in an Axiovert Zeiss microscope. Counting was performed in twenty arbitrarily chosen microscope fields for each sample.

\section{Trypan blue exclusion viability assay}

Caco- 2 cells were seeded in a 24 wells polypropylene plate and after 30 and $60 \mathrm{~min}$ of parasites addition they were detached from the wells by trypsin treatment. Detached cells were centrifuged and the pellet was resuspended in a $0.4 \%$ Trypan blue solution in sterile PBS for one min. Cells were then counted in a Neubauer hemocytometer chamber (NC), and the stained cells were considered dead. The number of stained cells was subtracted from the total, indicating the death ratio in each interaction condition and time.

\section{Transepithelial electrical resistance (TER)}

TER is an instantaneous measurement for the degree of tightness and paracellular flux across an epithelium [37]. We performed TER analysis in order to determine tight junction functionality during parasite interaction. Caco-2 cells were grown on transwell polycar- 
bonate filters (Costar, Cambridge, MA) until confluence was achieved. Next, the parasite:cell interaction was performed. TER values were determined every $30 \mathrm{~min}$ during $5 \mathrm{~h}$ using a Millicel-ERS voltmeter (Millipore), with $20 \mu \mathrm{A}$ constant current. Values were corrected for the effective growth area of the filter $\left(0.6 \mathrm{~cm}^{2}\right)$ after subtracting the resistance of the filter and bathing solution.

\section{Immunofluorescence microscopy}

Caco-2 cells were grown on sterile glass coverslips. After $60 \mathrm{~min}$ of interaction with the parasites, cells were washed in warmed PBS supplemented with $100 \mathrm{mM} \mathrm{CaCl}_{2}$ and $100 \mathrm{mM} \mathrm{MgCl}_{2}(\mathrm{PBS} / \mathrm{CM})$ and fixed in freshly made $4 \%$ paraformaldehyde overnight at $4{ }^{\circ} \mathrm{C}$. Cells were washed in PBS/CM, permeabilized with $0.075 \%$ saponine, and blocked with $50 \mathrm{mM}$ ammonium chloride and $1 \%$ and $3 \%$ BSA. Antibodies anti-E-cadherin (Sigma Chemical Co., St Louis, MO) diluted 1:500, anti-ZO-1 (ZYMED, San Francisco, CA) diluted 1:25 and anti-occludin (ZYMED, San Francisco, CA) diluted 1:50 were used as primary antibodies. Secondary IgG anti-rat or anti-rabbit fluorescent conjugated antibodies were used for $1 \mathrm{~h}$.

For AP65 localization, $T$. vaginalis culture tubes were chilled in ice-cold water and centrifuged at $150 \times \mathrm{g}$ for $5 \mathrm{~min}$. The pellet was ressuspended in warmed sterile PBS and spun down again at the same conditions. Cells were fixed overnight at $4{ }^{\circ} \mathrm{C}$ with $4 \%$ paraformaldehyde. Fixed parasites were washed in PBS and allowed to adhere on poly-L-lysine coated glass coverslips. Permeabilization was performed with $3 \% \mathrm{NP}-40$ and cold acetone for $30 \mathrm{~min}$ and quenching was done as described above. The AP65 antibody was kindly provided by Dr. J. F. Alderete (Texas University), used at 1: 20 dilution and protein visualized with TRITC-conjugated secondary antibody. The samples were observed using an Axiophot II Zeiss microscope, and the images were acquired with a Hamamatsu chilled C5985 CCD camera. Programs such KS300 and Adobe PhotoShop 7.0 were used to create pseudo-colored images.

\section{F-actin detection}

TRICT-phalloidin was used in order to analyze the distribution of F-actin after parasite interaction. Cell monolayers were washed with $\mathrm{PBS} / \mathrm{CM}$, fixed and permeabilized as above, and incubated with $500 \mathrm{ng} / \mathrm{ml}$ TRICT- phalloidin (Sigma Chemical Co., St Louis, MO) for $30 \mathrm{~min}$ at room temperature in the dark. After washes, samples were observed by fluorescence microscopy.

\section{Fluorescence quantification}

All images were acquired with the same exposure time, brightness and contrast. Computer analyses generated a three dimensional graphic. Each peak from the graphic represented the pixel intensities in a black (arbitrary unit, $\mathrm{AU}=0)$ and white $(\mathrm{AU}=255)$ scale, which could be associated with the fluorescence intensity. Peak values were collected from every image and plotted in a two dimensional graphic. ImageJ v.1.32j (National Institutes of Health, USA) software was used to perform fluorescence measurements.

\section{Scanning electron microscopy}

After parasite interaction, cells were fixed in Karnovsky solution (2.5\% glutaraldehyde, $1 \%$ paraformaldehyde, $5 \mathrm{mM}$ calcium chloride, $8 \%$ sucrose in $0.1 \mathrm{M}$ sodium cacodylate buffer, $\mathrm{pH} 7.2$ ), and postfixed with $1 \% \mathrm{OsO}_{4}$ in $0.1 \mathrm{M}$ sodium cacodylate buffer. Afterwards, cells were washed with PBS, dehydrated in ethanol and criticalpoint-dried using $\mathrm{CO}_{2}$. The samples were coated with gold-palla- dium and observed in a JEOL 5800 scanning electron microscope.

\section{Transmission electron microscopy}

After parasite interaction, Caco- 2 cells were fixed as described above, post-fixed in $1 \% \mathrm{OsO}_{4}$ in cacodylate buffer and $0.8 \%$ potassium ferricyanide for $30 \mathrm{~min}$, and dehydrated with acetone and embedded in Epon. Ultra-thin sections were stained with uranyl acetate and lead citrate, and observed in a Jeol 1210 electron microscope.

\section{Subcellular fractions and immunoblotting}

After interaction assays, samples were washed three times in $\mathrm{PBS} / \mathrm{CM}$ and incubated for $30 \mathrm{~min}$ at $4{ }^{\circ} \mathrm{C}$ in CSK buffer $(50 \mathrm{mM}$ $\mathrm{NaCl}, 10 \mathrm{mM}$ Pipes, pH 6.8, 3 mM MgCl $2,0.5 \%$ TX-100, $300 \mathrm{mM}$ sucrose, $1 \mathrm{mM}$ PMSF, $10 \mu \mathrm{g} / \mathrm{ml}$ leupeptin, $1 \mathrm{mM}$ orthovanadate). Cells were scratched from plates, homogenized and centrifuged at $12,000 \times \mathrm{g}$ for $10 \mathrm{~min}$ at $4^{\circ} \mathrm{C}$. The supernatant, which corresponds to the soluble fraction (TX-100 soluble fraction), was removed and stored at $4{ }^{\circ} \mathrm{C}$. The pellet was resuspended in $300 \mu 1 \mathrm{SDS}$ buffer $(20$ $\mathrm{mM}$ TrisHCl $\mathrm{pH}$ 7.5, $5 \mathrm{mM}$ EDTA, $2.5 \mathrm{mM}$ EGTA, 1\% SDS) and boiled at $100^{\circ} \mathrm{C}$ for $10 \mathrm{~min}$. The tubes were centrifuged again at $12,000 \times \mathrm{g}$ for $10 \mathrm{~min}$ and the supernatant, corresponding to the insoluble fraction (TX-100 insoluble fraction), was gently removed and stored at $4^{\circ} \mathrm{C}$.

Total fractions of $T$. vaginalis from both strains were also obtained before and after interaction with Caco- 2 cells. Parasites were centrifuged at $150 \times \mathrm{g}$ for $5 \mathrm{~min}$. The pellets were homogenized in cold CSK buffer for $30 \mathrm{~min}$ and samples stored at $4{ }^{\circ} \mathrm{C}$.

Total fractions of the parasites and TX-100 fractions were loaded on 7.5\% SDS-PAGE mini-gels and blotted on nitrocellulose membranes using a semi-dry gel transference device (BioRad, Hercules, CA). All nitrocellulose membranes were blocked for $1 \mathrm{~h}$ with TBS-T buffer $(20 \mathrm{mM}$ Tris-HCl, $\mathrm{pH} 7.6,137 \mathrm{mM} \mathrm{NaCl}$ and $0.1 \% \mathrm{v} / \mathrm{v}$ Tween 20) containing 5\% low-fat dried milk and incubated overnight with the following antibodies: polyclonal anti-occludin (dilution 1:10,000) (Zymed Laboratories, Inc.) and monoclonal antiAP65 (dilution 1:5,000) [37]. After washes, membranes were incubated for $1 \mathrm{~h}$ with peroxidase-conjugated goat anti-rabbit IgG (Zymed Laboratories, Inc.), respectively diluted 1:10,000 or goat anti-mouse IgG (Sigma Chemical Co., St Louis, MO) diluted 1:30,000. Proteins were visualized using an enhanced chemiluminiscence kit (Amersham Pharmacia Biotech, Bucks, UK) in order to proceed to autoradiography.

\section{RESULTS}

\section{Interaction assay}

Both JT and T016 isolates of T. vaginalis were able to interact with Caco- 2 cells. Among the four tested parasite densities, the highest rate of interaction was achieved with parasites: Caco cells at 10:1 ratio (Fig. 1A-D). During interaction, both isolates of $T$. vaginalis exhibited intense movement either in HI (high iron) or LI (low iron) conditions. Cell clusters could be observed in adhered as well as in non-adhered cells.

The T016 presented $29 \%$ more adhesion rate than strain JT when HI condition was used (Fig. 1A and 1C). T. vaginalis grown under LI conditions showed $35 \%$ and $25 \%$ less interaction for JT and T016, respectively (Fig. 


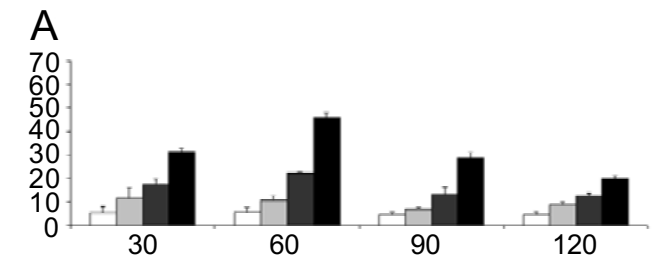

\section{$\mathrm{B}$}
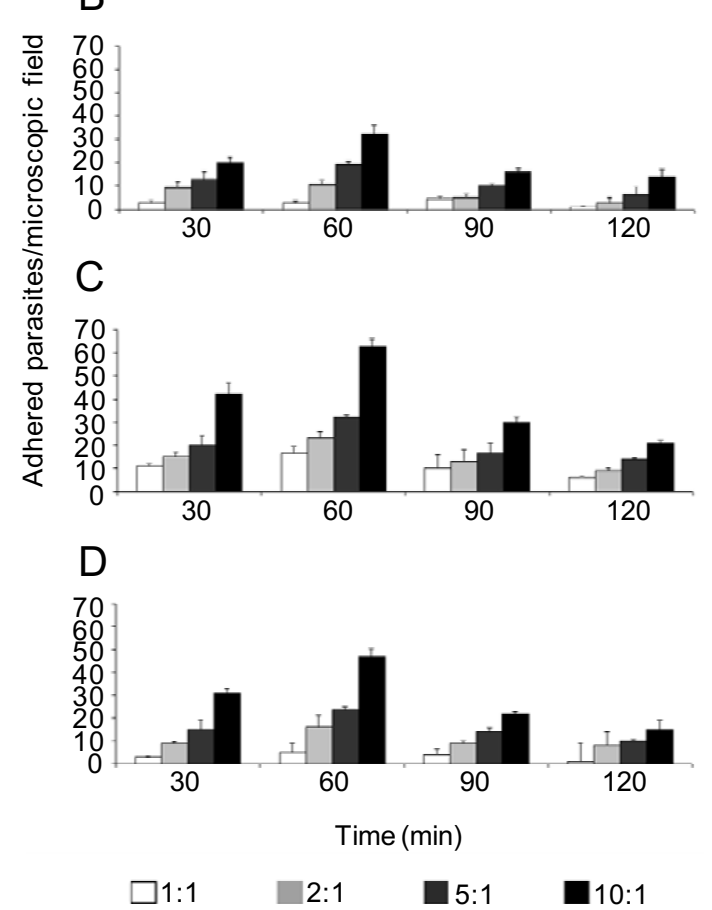

Fig. 1 Adhesion of T. vaginalis to Caco 2 epithelial cells. Adhesion was measured by counting aleatory microscopic fields. Four parasite: host cells ratios were used $(1: 1 ; 2: 1 ; 5: 1$ and 10:1). The strain JT (A, B) presented a small number of adhered parasites when compared with strain T016 (C, D). Iron concentration in the medium interferes with parasite adhesion, as observed comparing parasites grown in low iron $(\mathbf{B}, \mathbf{D})$ with those grown in high iron conditions $(\mathbf{A}, \mathbf{C})$. Iron concentration in the medium interferes with parasite adhesion, as observed in low iron (B, D) and high iron conditions (A, C).

1B and 1D) compared to HI grown parasites. After 90 min of interaction, parasite T016 adhesion decreased 37\% and $50 \%$ in high and low iron conditions, respectively. The other concentrations here used exhibited lower adhesion rates and were not explored in the experiments.

\section{AP65 expression is modulated by iron}

Expression of AP65 was used as a criterion to evaluate parasite's pathogenicity. The expression of this protein varied among isolates and was dependent of the iron concentration in the culture medium. Fig. 2A shows that expression of AP65 was more intense in the T016 than in the JT strain. In the case of parasites from T016, but not

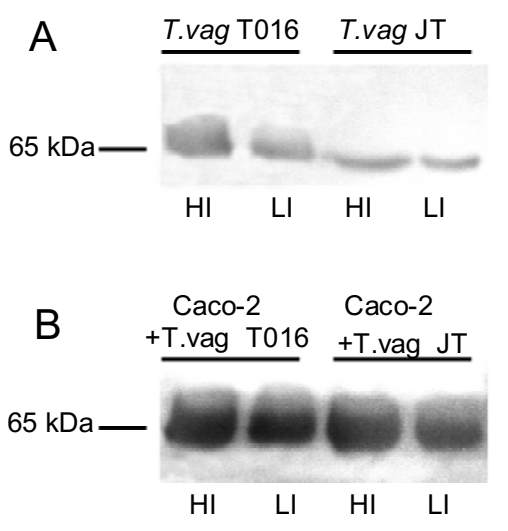

Fig. 2 Immunoblotting of total fractions of T. vaginalis before (A) and after (B) interaction with Caco-2 cells. (A) T016 parasites grown in high iron medium (HI) exhibited higher reactivity to anti-AP65 antibody than those cultivated in low iron (LI). The JT strain did not show differences in protein expression in both media. (B) After 60 min of interaction with epithelial cells, both strains expressed more AP65 than those cells that had no contact with the Caco-2 cells.

in those of the JT, labeling was more intense when the parasites were cultivated under $\mathrm{HI}$ conditions. After 60 min of interaction with Caco-2 cells, both strains expressed more AP65 than those cells that had no contact with the Caco-2 cells (Fig. 2B). Immunofluorescence analyses for AP65 also showed that the iron concentration modulates the expression of AP65. Parasites grown in HI conditions presented a more intense labeling than those grown in LI medium (Fig. 3A-D).

\section{T. vaginalis affects the transepithelial electrical re- sistance (TER)}

T. vaginalis in interaction with Caco- 2 cells seemed to provoke a progressive decrease of the TER (Fig. 4). The T016 and JT isolates grown in HI medium showed a TER reduction of $60 \%$ and $20 \%$, respectively, after $60 \mathrm{~min}$ of interaction whereas in LI medium these strains reduced the TER by $20 \%$ and $6 \%$, respectively. After $5 \mathrm{~h}$ of interaction, epithelial cells exposed to HI grown parasites showed a complete loss of TER, whereas under LI conditions the TER was reduced by $52 \%$ for strain JT, and $60 \%$ for T016 strain. These observations indicate that in both conditions the strain T016 appears to affect more the paracellular electrical flux of epithelial cells than JT. On the other hand, cell death seemed not to be the major cause of the TER decrease. Cultures of Caco-2 presented about $2 \%$ of dead cells in routine conditions. After 30 or $60 \mathrm{~min}$ of interaction with the parasites, it was not observed a considerable variation in cell death in both strains under different iron concentrations. A light increase $(3 \% \pm 0.015)$ 


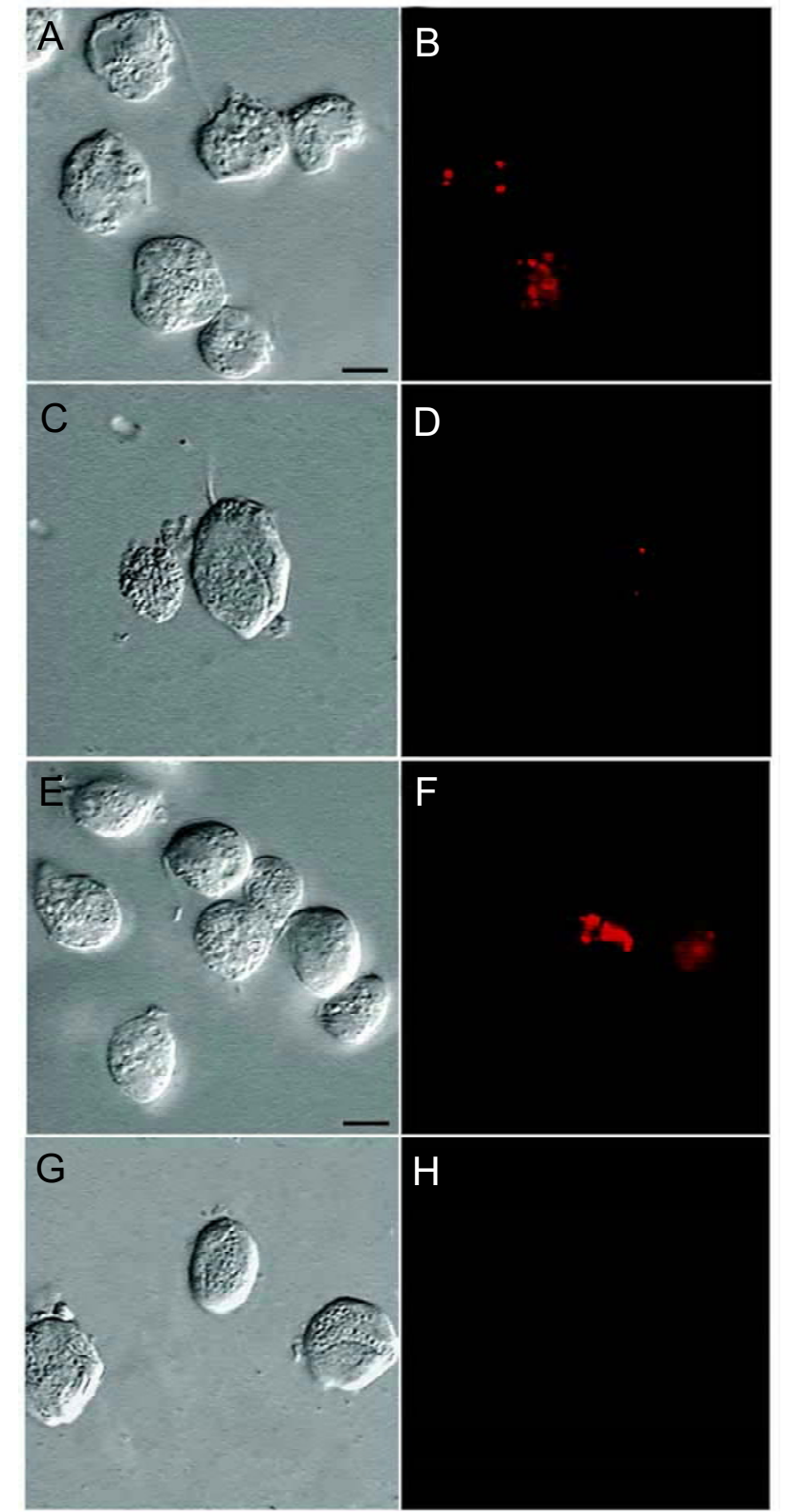

Fig. 3 DIC (A, C, E, G) and immunofluorescence microscopy (B, D, $\mathbf{F}, \mathbf{H})$ of $T$. vaginalis, strains JT (A-D) and T016 (E-H) grown under high (A-B; E-F) and low (C, D, G-H) iron conditions after immunolabeling with antibody anti-AP65. Notice that AP65 distribution is different in parasites grown in $\mathrm{HI}(\mathbf{B}, \mathbf{F})$ if compared with LI $(\mathbf{D}, \mathbf{H})$. Bar $=10 \mu \mathrm{m}$.

in cell death was found in T. vaginalis $\mathrm{T} 016$ when grown in HI. However, it was not considered a significant value.

\section{Decrease of TER is associated with disruption of cell- cell contacts}

When observed by scanning electron microscopy confluent Caco- 2 cells were seen closely apposed and ex- hibiting numerous apical microvilli (Fig. 5A). Both isolates of $T$. vaginalis (Fig. 5B) grown under different iron conditions induced morphological alterations at the junctional complex area (Fig. 5C and 5D). After 30 min of interaction parasites adhered to the monolayer were found in the proximity of the damaged regions and already adhered to the glass coverslips. After $60 \mathrm{~min}$ of interaction T. vaginalis displayed an amoeboidal shape (Fig. 5E). Furthermore, parasites of both strains adhered by the regions opposite to that where the recurrent flagellum is located (Fig. 5C and $5 \mathrm{E}$ ). The anterior flagella were seen in contact with host-cells (Fig. 5D-F).

We also analyzed these morphological alterations using transmission electron microscopy. Thin sections of $T$. vaginalis showed parasites with four anterior flagella, one nucleus, a well-developed Golgi complex, digestive vacuoles and hydrogenosomes distributed in the cytoplasm (Fig. 6A). Caco-2 cell monolayers demonstrated a junctional region with two cells in a very close contact. An intimate contact region in the upper portion of the cell-to-cell contact site corresponding to the tight junction was observed (Fig. 6B). Desmosomes were also present in these areas (Fig. 6C). After interaction, $T$. vaginalis from both isolates were observed over and in contact with the epithelium (Fig. 6D). Openings at the junctional site between adjacent cells were seen (Fig. 6E and 6F), as well modifications on parasite's membrane, which could increase the contact area when the cells acquired an amoeboidal shape (Fig. 6G).

\section{Junctional complex proteins are redistributed during parasite interaction}

It is well known that functionality of the junctional proteins is related to cytoskeleton arrangement. Thus, to further analyze the behavior of junctional proteins during interaction of $T$. vaginalis with Caco-2 cells, immunofluorescence microscopy was performed using anti-occludin (Fig. 7), anti-E-cadherin (Fig. 8), and anti-ZO-1 (Fig. 9) antibodies. Differential interferential contrast (DIC) microscopy of control T. vaginalis (Fig. 7A, 8A and 9A) and Caco-2 cells (Fig. 7B, 8B and 9B) were observed separately. A continuous and intense labeling at the cell-tocell contact region in confluent Caco-2 cultures (Fig. 7C, 8C and 9C) was observed. In addition, actin distribution was also analyzed after host-cell-parasite interaction. The distribution of actin in epithelial cells before parasite interaction is shown in Fig 7D, 8D and 9D. Labeling was seen in the cell border, at the same focal plane of the junctional proteins localization. Interestingly, few modifications in junctional complex proteins distribution were observed after $60 \mathrm{~min}$ of interaction. The proteins occludin (Fig. 7G, 7K, $7 \mathrm{O}$ and $7 \mathrm{~S}$ ), E-cadherin (Fig. 8G, 8K, $8 \mathrm{O}$ and $8 \mathrm{~S}$ ) and 


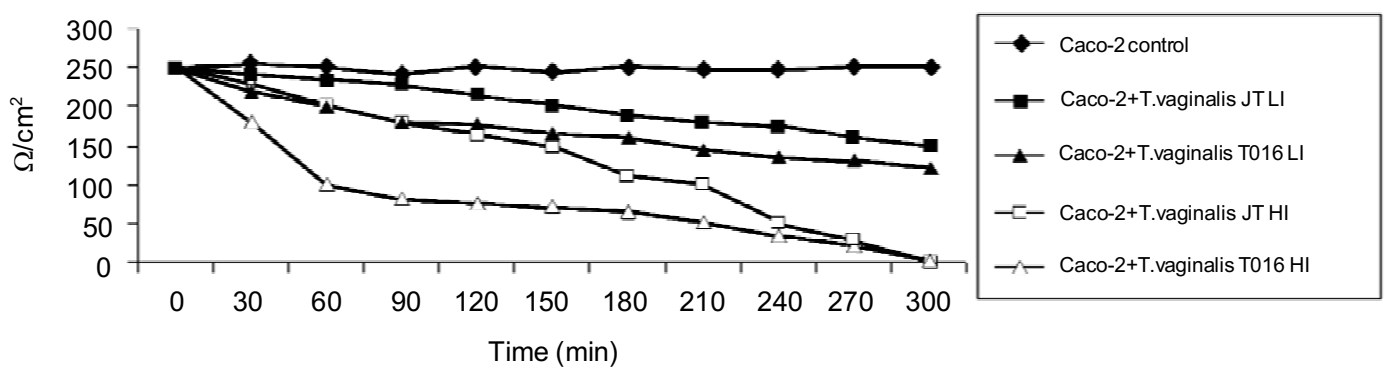

Fig. 4 Measurement of the transepithelial electrical resistance (TER) before and after parasite interaction with Caco cells. Control Caco-2 cells show a stable and continuous transepithelial electrical resistance (TER) of $250 \Omega / \mathrm{cm}^{2}$. T. vaginalis JT strain grown in low iron (LI) and T016 also grown in the same medium demonstrated low decrease after $60 \mathrm{~min}$ of interaction. Only after $300 \mathrm{~min}$ some evident decrease $(52 \% \pm 0.05$ and $60 \% \pm 0.04$ respectively) was observed when compared to the control. Strain JT in high iron (HI) showed a slight decrease after one hour of interaction $(20 \% \pm 0.05)$ whereas strain T016 in HI decreased TER by $60 \% \pm 0.08$. Total loss of TER was achieved after $300 \mathrm{~min}$ of parasite interaction. Only HI grown parasites were able to induce complete reduction of TER.
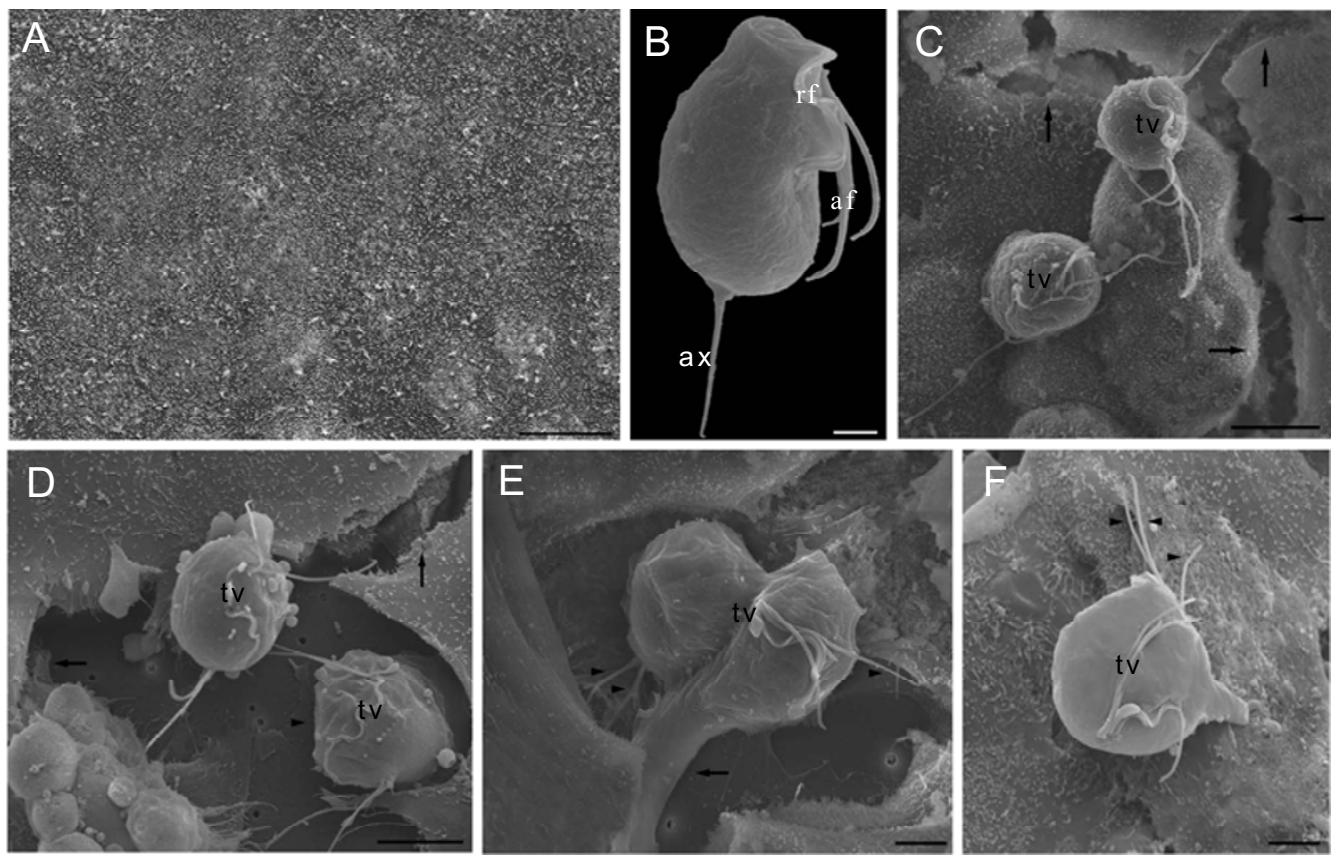

Fig. 5 Scanning electron microscopy of Caco-2 cells before (A) and after interaction with T. foetus (C-F). In Fig. 6A Caco-2 cells are confluent and no gaps are observed between neighbor cells. (B) T. vaginalis before interaction with epithelial cells showing the recurrent flagellum (rf), four anterior flagella (af) and the axostyle at the posterior portion of the cell body (ax). (C, D) After 30 min of interaction $T$. vaginalis (TV) are seen adhered to epithelial cells where injury is already observed, with the appearance of gaps between cells (arrows). Note that parasites can be found also adhered to the film where Caco-2 cells were grown (arrowhead). E shows that parasites (TV) can be found adhered to epithelial cells by its flagella (arrowheads, F) or through the posterior region of the cell (arrow).

$\mathbf{A}, \mathbf{C}, \mathbf{D}, \mathbf{E}, \mathbf{F}$, bar $=10 \mu \mathrm{m} . \mathbf{B}$, bar $=2 \mu \mathrm{m}$.

ZO-1 (Fig. 9G, 9K, 9O and 9S) exhibited slight alterations in their distribution pattern, but not sufficient to cause actin cytoskeleton rearrangement (Fig. 7-9). These results suggest that the alterations in occludin, E-cadherin and ZO1 proteins distribution on the site of parasite adhesion seemed to be responsible for the TER decrease. Decrease in occludin, E-cadherin and ZO-1 fluorescence intensity was also detected in these sites (Fig. 10A-C), as seen to computer based fluorescence analysis, suggesting a spatial rearrangement of these three proteins. 


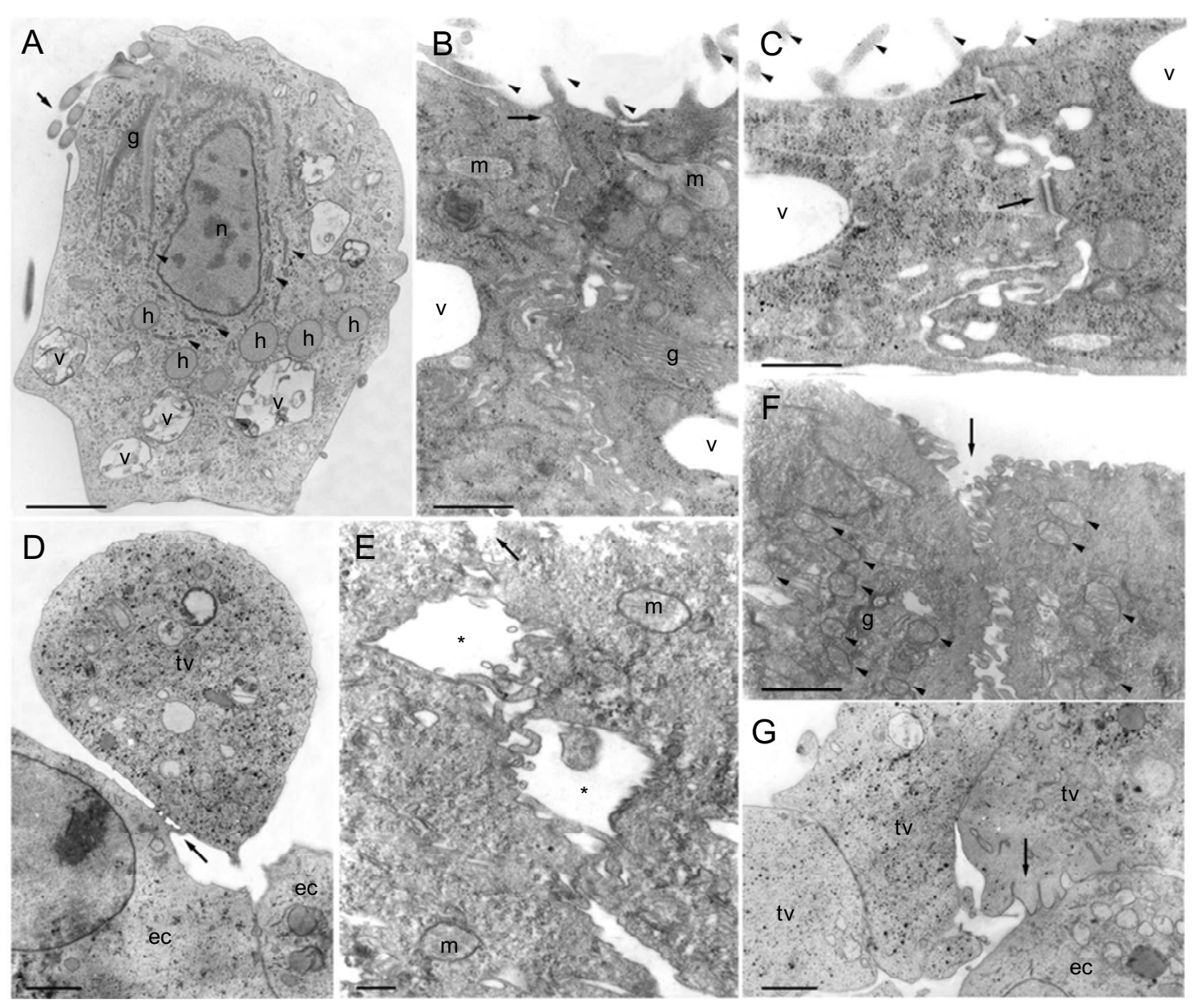

Fig. 6 Transmission electron microscopy of $T$. vaginalis $\mathbf{( A )}$ and Caco-2 cells $\mathbf{( B ,} \mathbf{C})$ before interaction. T. vaginalis presents one nucleus (n), a well developed Golgi complex (g), hydrogenosomes (h), digestive vacuoles (v), endoplasmic reticulum surrounding the nucleus (arrowheads) and four anterior flagella (arrow); In B and C a confluent culture of Caco-2 cells shows microvilli (arrowheads), junctional areas (arrows), mitochondria (m), vacuoles (v) and Golgi complex (g). A tight junction is seen in B and desmosomes in C and $\mathrm{D}$ shows a parasite (tv) after $30 \mathrm{~min}$ interaction with Caco-2 cells (ec) adhered through short membrane projections (arrow). (E, F) After $60 \mathrm{~min}$ of interaction large intercellular spaces are seen between the epithelial cells $\left(^{*}\right)$. Mitochondria show signs of disturbance, such as internal vesiculation (arrowheads, F). Golgi complex (g). (G) T. vaginalis (tv) are seen in clusters and also adhered (arrow) to epithelial cells (ec). Bar $=1.5 \mu \mathrm{m}$.

\section{Occludin protein distribution}

Immunoblotting of occludin was done using TritonX100 soluble and insoluble fractions of Caco-2 cells before and after parasite interaction (Fig. 11A and 11B). Similar results were found in both control and experimental groups.

\section{DISCUSSION}

The Caco-2 cell line when in confluence is able to develop a functional junctional complex. Although this cell line was not derived from urogenital tract, it is one of the better characterized cell lines that have been widely used in studies on disassembly of junctional complexes. The present work shows that $T$. vaginalis in contact with the apical side of Caco-2 cells monolayers rapidly induces a decrease in the TER. This effect was associated with alterations in the distribution of junctional complex proteins of the epithelial cell and seemed to be dependent of the parasite virulence and the iron concentration of the medium where the parasite is cultivated.

The decrease of TER during the host-parasite interaction here observed seemed to be dependent on the parasite-cell ration and incubation time. However, it was not dependent on the parasite virulence, since cell death was 

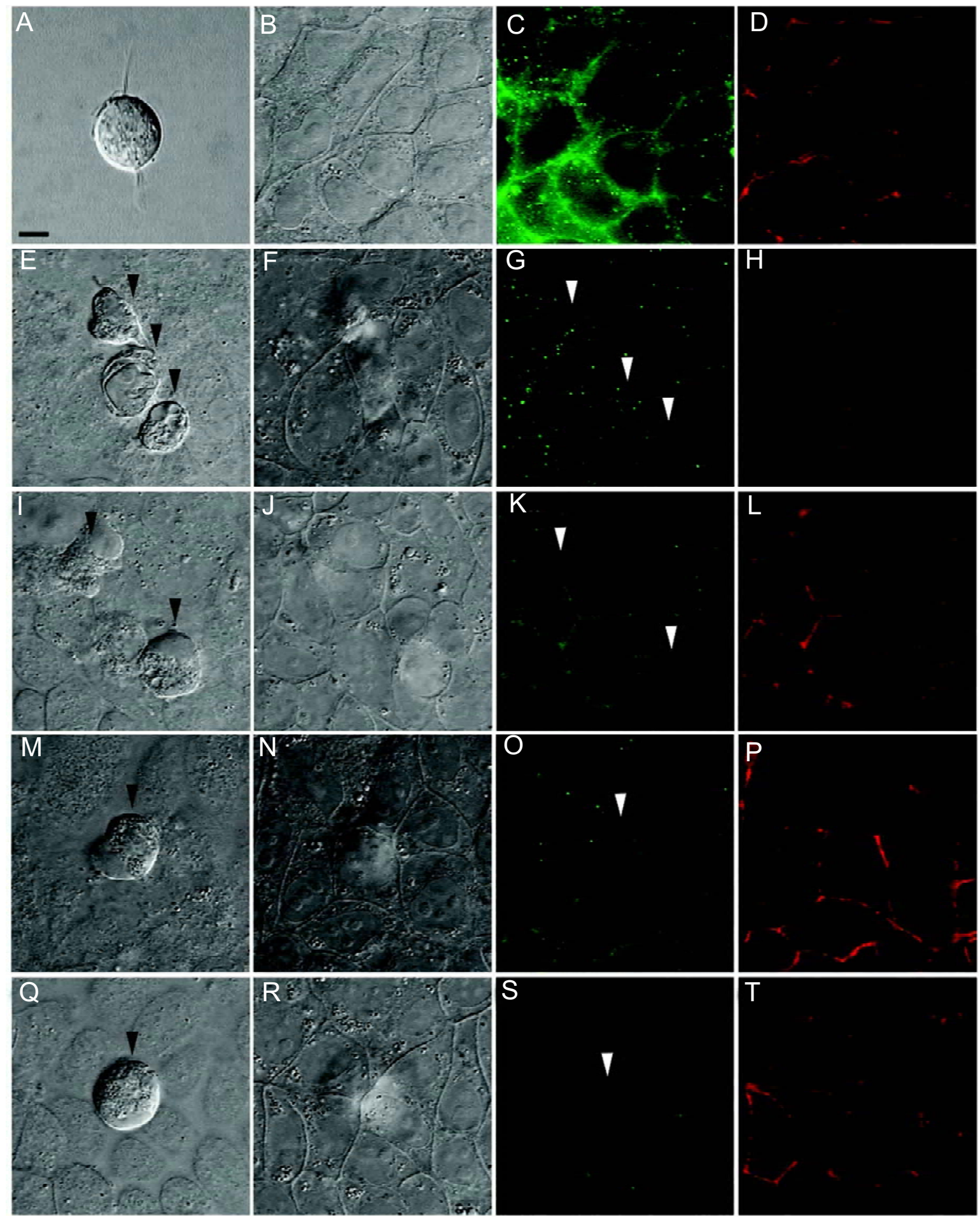

Fig. 7 Immunofluorescence microscopy showing occludin and actin distribution before (A-D) and after (E-T) interaction with $T$. vaginalis. A shows control T. vaginalis and (B-D) the Caco-2 cells in a confluent monolayer. In $\mathrm{C}$ an intense labeling for occludin is observed surrounding epithelial cells. Actin is also positive in the same region (D). E-L: after $60 \mathrm{~min}$ of T. vaginalis interaction with Caco-2 cells: strain JT (black arrow heads), grown in high iron (E-H) or low iron (I-L). Parasites were seen adhered to the epithelium (F-J), causing slightly decrease (white arrow heads) of occludin labeling, whereas no alteration in actin staining was depicted (H-L). MT: when the $T$. vaginalis strain T016 was used under the same experimental conditions of high iron (M) and low iron (Q), the same effects were observed (M-T). Bar $=5 \mu \mathrm{m}$. 


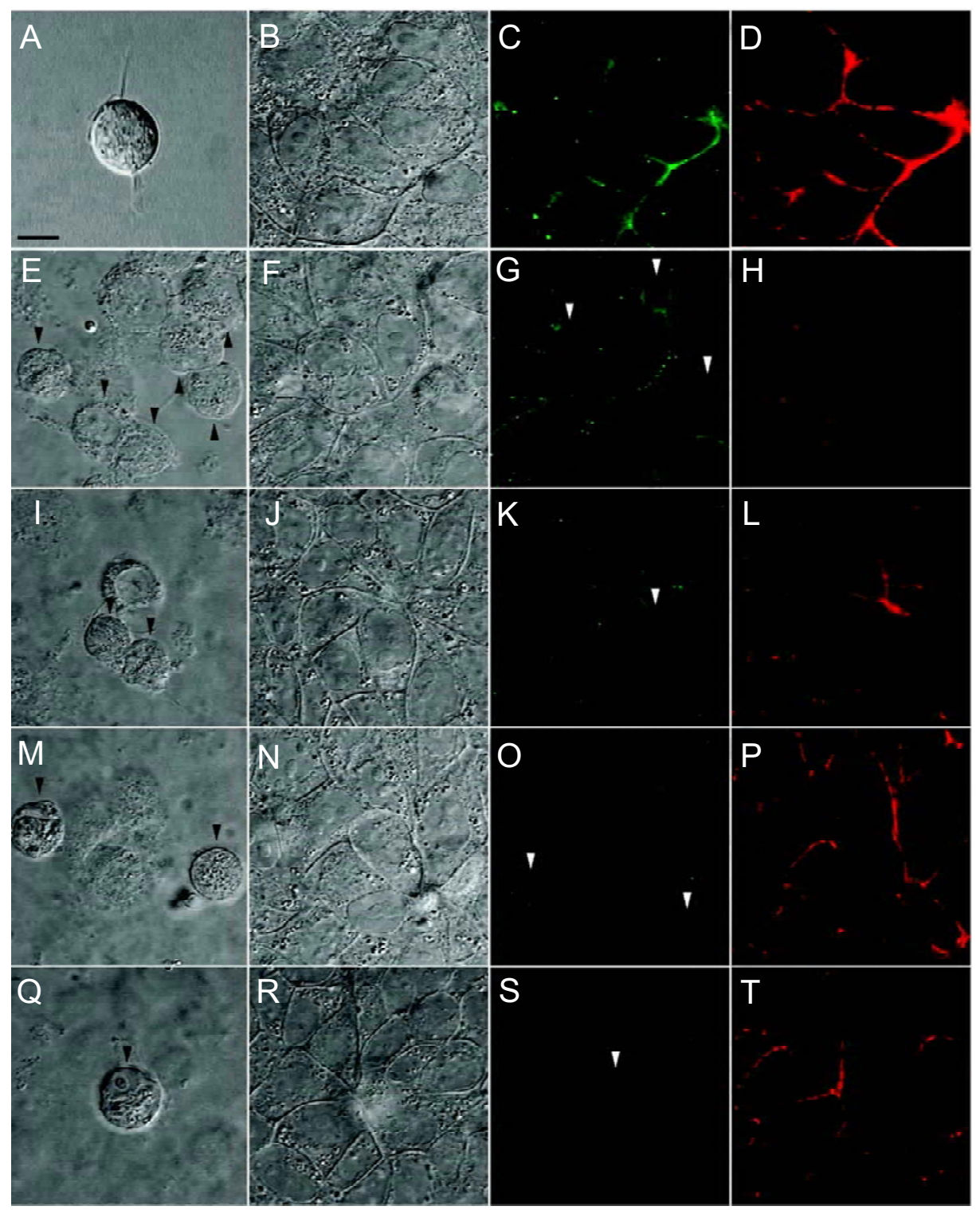

Fig. 8 Distribution of E-cadherin in Caco-2 cells after 60 min of parasite interaction. A and B show T. vaginalis and control Caco-2 cells by DIC. Immunofluorescence of E-cadherin (C) and actin (D) exhibits the same peripheral distribution in control Caco-2 cells. Different focal planes at the same microscopic field show adhered parasites (black arrow heads) of strain JT grown in HI medium (E), LI medium (I) and the respective epithelium (F, J). E-cadherin distribution is seen by light spotted modifications (white arrow heads) close to the parasite's adhesion site (G, K). Strain T016 HI (M) and LI (Q) caused little discontinuity in E-cadherin distribution (O and $\mathbf{S}$ respectively). Actin was not perturbed in all conditions $(\mathbf{H}, \mathbf{L}, \mathbf{P}, \mathbf{T}) . \mathrm{Bar}=5 \mu \mathrm{m}$.

observed after 60 min of interaction with both JT and T016 isolates. Similar results were found during the interaction of virulent and avirulent strains of $T$. vaginalis with MDCK cultures [39, 40] and E. histolytica with human enteric T84 cell layer [16]. An interesting observation was the decrease in the number of adhered parasites observed after $60 \mathrm{~min}$ of interaction. It is possible that some not yet elucidated factors could interfere with parasite adhesion.
It is well known that $T$. vaginalis populations are heterogeneous in various aspects, such as $\mathrm{P} 270$ protein expression [17], drug resistance [41], adhesion capacity and pathogenicity [42]. Thus, we propose that the small population that remains adhered to Caco- 2 cells could be a subgroup capable of to lose their own molecular machinery of specific host recognition. It is known that expression of AP65, a protein involved in the parasite adhesion [43], 


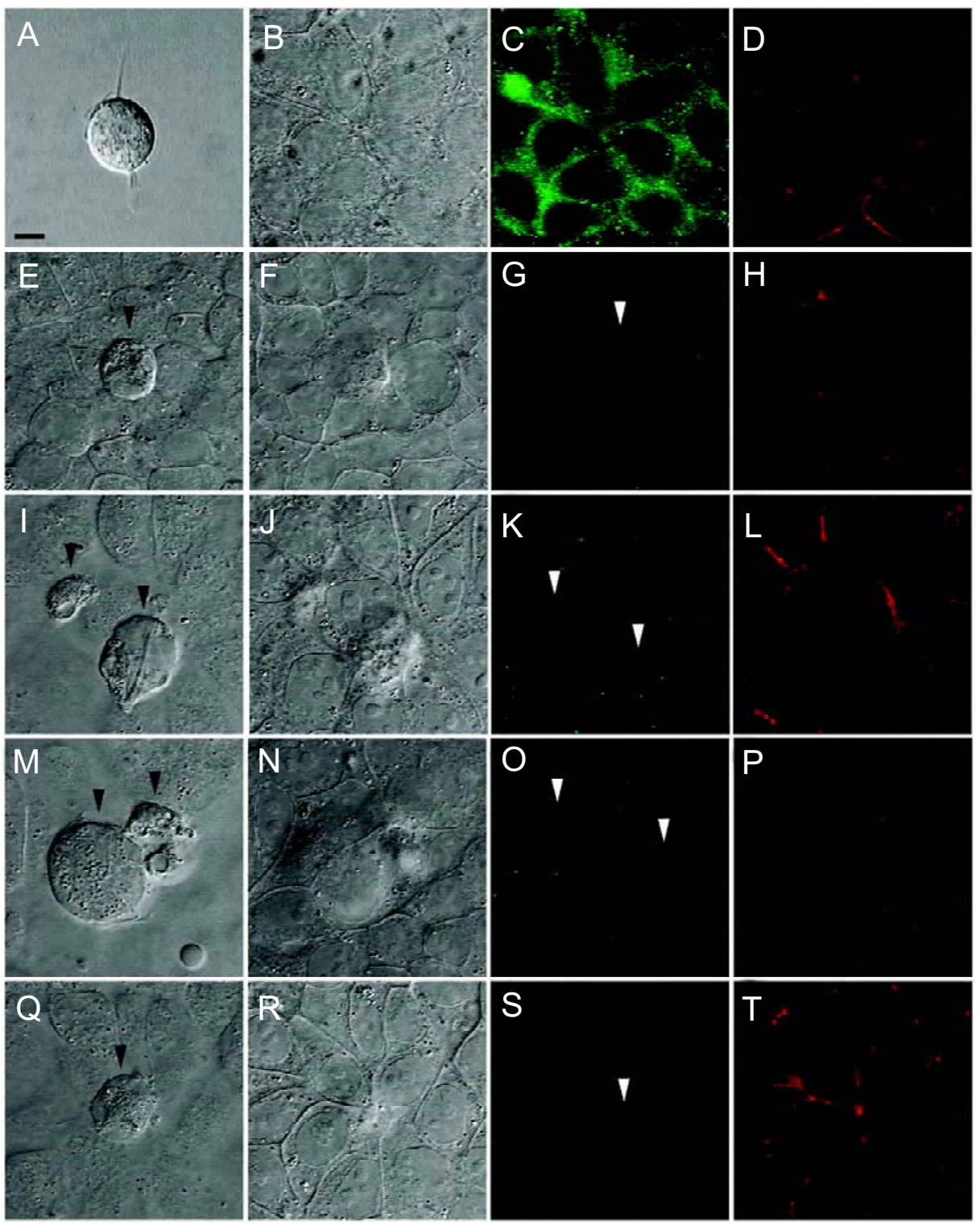

Fig. 9 Immunolabeling of ZO-1 after T016 strain (parasite) 60 min interaction with Caco-2 cells. A and B show respectively $T$. vaginalis and confluent Caco-2 cells before interaction. ZO-1 was detected in the peripheral region of epithelial cells (C) and actin was also observed at the same site (D). After parasite adhesion ZO-1 labeling was decreased. Figures E and I show JT strain of T. vaginalis grown in $\mathrm{HI}$ and LI grown medium (black arrow heads), respectively, adhered to the epithelium (F, J). ZO-1 is shown in G and $\mathrm{K}$. Strain T016 in HI (M) and LI (Q) (black arrowheads) also exhibit similar results. Labeling is shown in $\mathbf{O}$ and $\mathbf{S}$. White arrowheads show the region of parasite contact and damage. Actin distribution seems not perturbed $(\mathbf{H}, \mathbf{L}, \mathbf{P}, \mathbf{T})$. Bar $=5 \mu \mathrm{m}$.

is modulated by the iron concentration and virulence of the parasite. As observed in the present work, a decrease in the expression of this protein was also related to a decrease in the adhesion rate supporting the idea that iron plays an important modulator effect on the parasite adhesion capacity, as previously suggested [18].

Although few changes in the localization and organization of junctional complex proteins were observed, it does not exclude that functional changes take place after interaction of $T$. vaginalis with Caco-2 cells. In co-cultures of E. histolytica with T84 cells, Leroy et al. [15] observed no changes in the pattern of distribution of tight junction proteins, but a decrease of the TER was detected. Here, major effects were observed by scanning electron microscopy where large intercellular spaces were seen after parasite-cell interaction. Similar observations were previously 
A
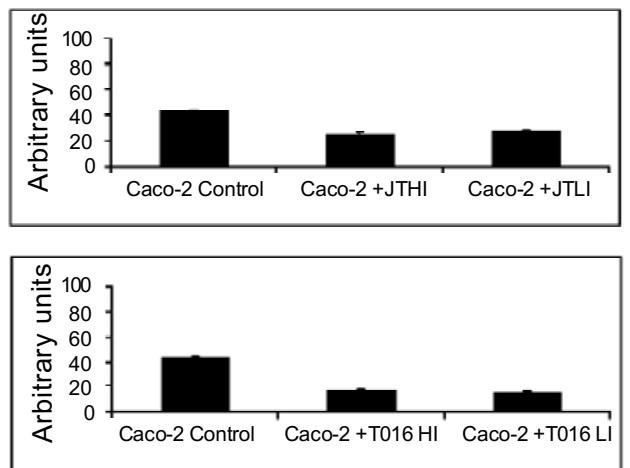

B
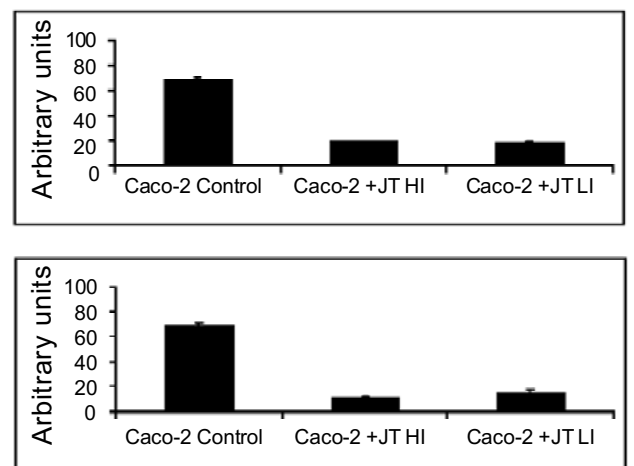

C
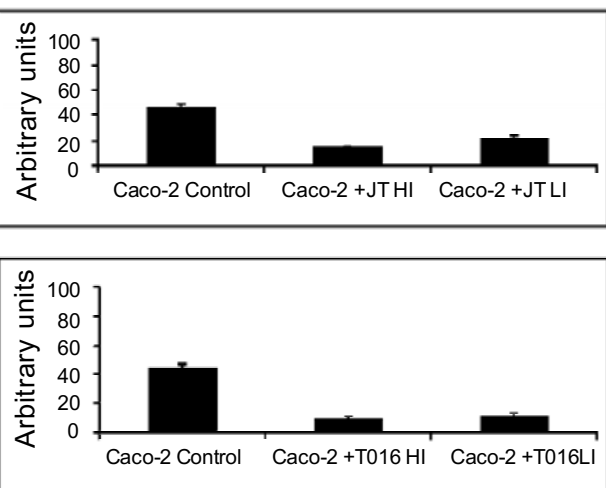

Fig. 10 Computer based fluorescence analysis. Occludin (A), Ecadherin (B) and ZO-1 (C) immunofluorescence images were analyzed and quantified by an image processing software and arbitrary units were used for comparison. Reduced labeling intensity was observed in all samples compared to the control. High iron (HI) grown parasites caused more reduction than those grown in low iron (LI). The strain T016 presented more reduction than strain JT. Values are mean \pm SD of 50 microscopic fields analyzed.

reported [40, 41]. This reaction, as well the decrease in labeling for junctional proteins at the parasite- Caco-2 cells interaction area, could be sufficient to explain alterations in TER.

Previous studies have shown that disruption of the junc-

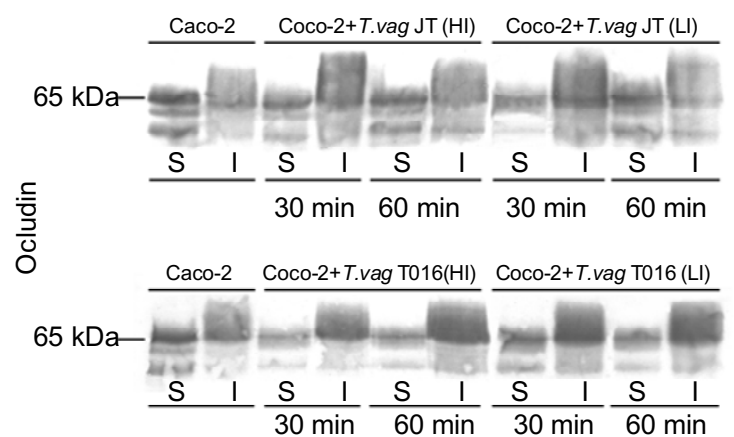

Fig. 11 Immunoblotting of Caco-2 cells before and after interaction with $T$. vaginalis using anti-occludin antibody. There were no considerable changes in occludin localization. Soluble (S) and insoluble (I) fractions of Caco-2 extracted after interaction with either high (HI) or low iron (LI) media grown parasites did not differ from control Caco-2 cells, thus suggesting no protein translocation.

tional complex of different cell lines takes place when they are submitted to several conditions, including removal of calcium [44-46]. Several other changes are associated with such disruption as (1) loss of membrane association of the junctional complex-associated proteins; (2) a loss of TJ strands, visualized in freeze-fracture replicas; (3) a decrease in the TER; and (4) a dramatic increase in transepithelial permeability to tracers. In the present work, attempts were done in order to determine whether the alterations in junctional complex proteins distribution were correlated with changes in the cytoskeleton. Occludin, a TJ protein, was detected mainly in the TX-100 insoluble fractions after interaction, indicating that, under the experimental conditions here used, the interaction between occludin and the cytoskeleton seemed to be not modified. This is in agreement with the previous experiments where calcium was removed, showing that disruption of the junctional complex did not correlate with translocation of this protein.

Previous studies using the same cell line herein used, demonstrated that several agents could disturb the junctional complex. It was shown that $\mathrm{NH}_{4} \mathrm{VO}_{3}$ or TPA treatment caused alteration to adherent junctions, but not to the tight junctions, suggesting that these two types of junctions are independently regulated [47-49].

In addition, these studies demonstrated that junctional proteins are modulated by phosphorylation in tyrosine. We have previously reported the existence of a link between PKC and EGFR signaling to modulate the assembly of intercellular junction in Caco-2 cells via MAPK [50]. It remains to be elucidated if these events occur during the interaction of $T$. vaginalis with this epithelial cell. 


\section{ACKNOWLEDGEMENTS}

This work was supported by Fundação Ary Frauzino para Pesquisa e Controle do Câncer- Instituto Nacional de Câncer, Fundação Carlos Chagas Filho de Amparo à Pesquisa do Estado do Rio de Janeiro (FAPERJ), Conselho Nacional de Desenvolvimento Científico e Tecnológico (CNPq), and Associação Universitária Santa Ùrsula (AUSU).

Received, June 20, 2005

Revised, Aug 18, 2005

Accepted, Sep 11, 2005

\section{REFERENCES}

1 Gilbert RO, Elia G, Beach DH, Klaessing S, Singh BN. Cytopathogenic effect of Trichomonas vaginalis on human vaginal epithelial cells cultured in vitro. Infect Immun 2000; 68:4200-6.

2 Zhang Z, Begg CB. Is Trichomonas vaginalis a cause of cervical neoplasia? Results from a combined analysis of 24 studies. Int $\mathrm{J}$ Epidemiol 1994; 23:682-90.

3 Coteh MF, Pastorek JG, Nugent, RP, et al. Trichomonas vaginalis associated with low birth weights and preterm delivery. Sex Transm Dis 1997; 24:353-360.

4 Minkoff H, Grunebaum AN, Schwartz RH, et al. Risk factors for prematurity and premature rupture of membranes: a prospective study of the vaginal flora in pregnancy. Am J Obstet Gynecol 1984; 150:965-72.

5 Goldstein F, Goldman MB, Cramer DW. Relation of tubal infertility to a history of sexually transmitted diseases. Am J Epidemiol 1993; 137:577-84.

6 Gram I, Macaluso M, Churchill J, Stalberg H. Trichomonas vaginalis (TV) and human papilloma virus (HPA) infection and the incidence of cervical intraepithelial neoplasia (CIN) grade III. Cancer Causes Control 1992; 3:231-6.

7 Kharsany AB, Hoosen AA, Moodley J, Bagaretee J, Gouws E. The association between sexually transmitted pathogens and cervical intra-epithelial neoplasia in a developing community. Genitourin Med 1993; 69:357-60.

8 Draper D, Donohoe W, Mortimeer L, Heine RP. Cystein proteinases of Trichomonas vaginalis degrade secretary leucocyte protease inhibitor. J Infect Dis 1998; 178:815-9.

9 Sorvillo F, Kovaes A, Kernd P, et al. Risk factors for trichomoniasis among women with HIV infection at a public clinic at Los Angeles County, California: implications for HIV prevention. Am J Trop Med Hyg 1998; 58:495-500.

10 Wang CC, McClelland RS, Reilly M, et al. The effect of treatment of vaginal infections on shedding of human immunodeficiency virus type-1. J Infect Dis 2001; 183:1017-22.

11 Petrin D, Delgaty K, Bhatt R, Garber G. Clinical and microbiological aspects of Trichomonas vaginalis. Clin Microbiol Rev 1998; 11:300-17.

12 Alderete JF, Garza G. Identification and properties of Trichomonas vaginalis proteins involved in cytoadherence. Infect Immun 1988; 56:28-33.

13 Silva Filho FC, De Souza W. The interaction of Trichomonas vaginalis and Tritrichomonas foetus with epithelial cells in vitro. Cell Struct Funct 1988; 13:301-10.
14 Krieger JN, Ravdin J, Rein MF. Contact dependent cytopathogenic mechanisms of Trichomonas vaginalis. Infect Immun 1985; 50: $768-70$.

15 Leroy A, Lauwaet T, De Bruyne G, Cornelissen M, Mareel M. Entamoeba histolytica disturbs the tight junction complex in human enteric T84 cell layers. FASEB J 2000; 14:1139-46.

16 Guenthner PC, Secor WE, Dezzutti CS. Trichomonas vaginalisinduced epithelial monolayer disruption and human immunodeficiency virus type 1 (HIV-1) replication: implications for the sexual transmission of HIV-1. Infect Immun 2005;73:4155-60.

17 Beachney EH, Giampapa CS, Abraham SN. Bacterial adherence. Adhesin receptor-mediated attachment of pathogenic bacteria to mucosal surfaces. Am Rev Respir Dis 1988; 138:S45-8 .

18 Lehker MW, Alderete JF. Iron regulates growth of Trichomonas vaginalis and the expression of immunogenic trichomonad proteins. Mol Microbiol 1992; 6:123-32.

19 Ryu JS, Choi HK, Min DY, et al. Effect of iron on the virulence of Trichomonas vaginalis. J Parasitol 2001 87:457-60.

20 Sobel JD. Current concepts: vaginitis. N Engl J Med 1997; 337: 1896-1903.

21 Fasano A. Intestinal zonulin: open sesame! Gut 2001; 49:159-62.

22 Fasano A, Baudry B, Pumplin DW, et al. Vibrio cholerae produces a second enterotoxin, which affects intestinal tight junctions. Proc Natl Acad Sci U S A 1991; 88:5242-6.

23 Furtado MB, Benchimol M. Observation of membrane fusion in the interaction of Trichomonas vaginalis with human vaginal epithelial cells. Parasitol Res 1997; 84:213-20 .

24 Yap AS, Brieher WM, Gumbiner BM. Molecular and functional analysis of cadherin-based adherens junctions. Annu Rev Cell Dev Biol 1997; 13:119-46.

25 Conacci-Sorrell M, Zhurinsky J, Ben-Ze'ev A. The cadherincatenin adhesion system in signaling and cancer. J Clin Invest 2002; 109:987-91.

26 Perez-Moreno M, Jamora C, Fuchs E. Sticky business: orchestrating cellular signals at adherens junctions. Cell 2003; 112:53548.

27 Tsukita S, Furuse M, Itoh M. Multifunctional strands in tight junctions. Nat Rev Mol Cell Biol 2001; 2:285-93.

28 Gonzalez-Mariscal L, Betanzos A, Nava P, Jaramillo BE. Tight junction proteins. Prog Biophys Mol Biol 2003; 81:1-44.

29 Furuse M, Fujita K, Hiragi T, Fujimoto K, Tsukita S. Claudin-1 and -2: novel integral membrane proteins localizing at tight junctions with no sequence similarity to occludin. J Cell Biol 1998; 141:1539-50.

30 Mostov K, Su T, Beest M. Polarized epithelial membrane traffic: conservation and plasticity. Nat Cell Biol 2003; 5:287-93.

31 Furuse M, Hirase T, Itoh M, et al. Direct association of occludin with ZO-1 and its possible involvement in the localization of occludin at tight junction. J Cell Biol 1994; 127:1617-26.

32 Haskins J, Gu L, Wittchen ES, Hibbard J, Stevenson BR. ZO-3, a novel member of the MAGUK protein found at the tight junction, interacts with ZO-1 and occludin. J Cell Biol 1998; 141:199208.

33 Gumbiner B, Lowenkopf T, Apatira D. Identification of a 160$\mathrm{kDa}$ polypeptide that binds to the tight junction protein $\mathrm{ZO}-1$. Proc Natl Acad Sci U S A 1991; 88:3460-4.

34 Yamamoto T, Harada N, Kano K, et al. The ras target AF-6 interacts with ZO-1 and serves as a peipheral component of tight junction in epithelial cells. J Cell Biol 1997; 139:785-795. 
35 Takeichi M. Cadherin cell adhesion receptors as a morphogenetic regulator. Science 1991; 251:1451-5.

36 Madara JL. Regulation of the movement of solutes across tight junctions. Annu Rev Physiol 1998; 60:143-59.

37 Diamond LS. The establishment of various Trichomonas of animals and man in axenic cultures. J Parasitol 1957; 43:488-90.

38 Crouch ML, Benchimol M, Alderete JF. Binding of fibronectin by Trichomonas vaginalis is influenced by iron and calcium. Microb Pathog 2001; 31:131-44.

39 Balda MS, Whitney JA, Flores C, et al. Functional dissociation of paracellular permeability and transepithelial electrical resistance and disruption of the apical-basolateral intramembrane diffusion barrier by expression of a mutant tight junction membrane protein. J Cell Biol 1996; 134:1031-49.

40 González-Robles A, Lazaro-Haller A, Espinosa-Cantellano M, Anaya-Velazquez F, Martinez-Palomo A. Trichomonas vaginalis: ultrastructural bases of the cytophatic effect. J Eukaryot Microbiol 1995; 42:641-51.

41 Gonzáles-Robles A, Espinosa-Cantellano M, Arguello C, et al. Surface properties and in vitro cytophatic effect of various strains of Trichomonas vaginalis. J Submicrosc Cytol Pathol 2004; 36: 77-83.

42 Johnson PJ. Metronidazole and drug resistance. Parasitol Today 1993; 9:183-6.

43 Rojas L, Sariego I, Fraga J, et al. Use of in vitro cytoadherence assays in the comparative study of the virulence of isolates of Trichomonas vaginalis. Parasitol Res 2004; 93:332-7.

44 Garcia AF, Chang TH, Benchimol M, et al. Iron and contact with host cells induce expression of adhesins on surface of Trichomonas vaginalis. Mol Microbiol 2003; 45:1207-24.

45 Klinger C, Kniesel U, Bamforth SD, et al. Disruption of epithelial tight junctions is prevented by cyclic nucleotide-dependent protein kinase inhibitors. Histochem Cell Biol 2000; 113:349-61.

46 Ivanov AI, Nusrat A, Parkos CA. Endocytosis of epithelial apical junctional proteins by a clathrin-mediated pathway into a unique storage compartment. Mol Biol Cell 2004; 15:176-88.

47 Peterson AD, Parton RG, Ferguson C, Stow JL, Yap AS. Characterization of E-cadherin endocytosis in isolated MCF-7 and chinese hamster ovary cells. J Biol Chem 2003; 278:19347-51.

48 Gómez S, Llosa MM, Verdú J, et al. Independent regulation of adherens and tight junctions by tyrosine phosphorylation in Caco-2 cells. Biochim Biophys Acta 1999; 1452:121-32.

49 Morgado-Díaz JA, De Souza W. Evidence that increased tyrosine phosphorylation causes disassembly of adherents junctions but does not perturb paracelular permeability in Caco-2 cells. Tissue Cell 2001; 33:500-13.

50 Barbosa LA, Goto-Silva L, Redondo PA, et al. TPA-induced signal transduction: a link between PKC and EGFR signaling modulates the assembly of intercellular junctions in Caco-2 cells. Cell Tissue Res 2003; 312:319-31.

Edited by Jian Guo GENG 